\title{
LAS DESTRUCCIONES DE LA ESTATUARIA IBÉRICA EN EL LEVANTE PENINSULAR*
}

\author{
JULIÁN TALAVERA COSTA \\ Universidad de Valencia
}

\begin{abstract}
Son numerosas las hipótesis sobre la destrucción de la estatuaria ibérica. Basándonos en una zona geográfica, y no exclusivamente en una necrópolis, mostramos el estado de la cuestión, las diferentes cronologías de la reutilización, asi como si se trata o no de un proceso dirigido hacia zonas concretas de los monumentos.
\end{abstract}

There one different hypothesis regarding the destructionof iberic sculptures. In order to study these hypothesis the present study doesn't focus on a single necropolis out on a whole geographical area, and explains at which point the investigations are right now, the different dates at which the sculptures were used and tries to show whether the destruction was as not centured only on certain parts of the sculptures.

\begin{abstract}
"Otros sacrilegios de Cambises:
Muchas fueron, en suma, las locuras de esta indole que cometió Cambises, tanto contra los persas como contra sus aliados, durante su estancia en Menfis, donde no sólo abrió antiguas tumbas, sino que hasta examinó sus cadáveres. Y es más, con la misma irreverencia, penetró incluso en el santuario de Hefesto, y se burló mucho de su estatua. (Resulta que la estatua de Hefesto es muy similar a los patecos de Fenicia, que los fenicios llevan en las proas de sus tirremes; $y$ para quien no haya visto patecos he de indicar que consisten en la imagen de un pigmeo). Y penetró asimismo en el santuario de Cabiros donde, de acuerdo con la norma establecida, no puede entrar nadie más que el sumo sacerdote; y hasta hizo quemar sus estatuas después de haberse mofado mucho de ellas. Por cierto que estas estatuas también se asemejan a las de Hefesto, de quien según dicen son hijos los cabiros". (Heródoto, Historias III, $37)$.
\end{abstract}

\section{LA DESTRUCCIÓN COMO UN PROCESO DIALÉCTICO}

Uno de los problemas a los que nos enfrentamos a la hora de abordar el estudio de la destrucción de las esculturas es establecer a qué nivel o niveles afecta este proceso. Por una parte repercute en el más puro sentido religioso, puesto que las únicas esculturas que aparecen destruidas son las que tuvieron una ubicación primitiva en las necrópolis. ¿Significa esto un cambio en la religiosidad?. Quizá no sea una revolución iconoclasta la causante del destrozo, ruina y nunca más erección de estas esculturas; sino que este fenómeno, la destrucción, es consecuencia de un primer proceso nada aclarado, que no tiene por qué ser en su génesis exclusivamente religioso, pero que acaba teniendo una vertiente religiosa. $\mathrm{O}$ bien admitimos que esta idea, esta asociación entre escultura y religión, es correcta, o bien renunciamos al supuesto carácter funerario, apotropaico y por tanto sacro de las esculturas.

El segundo ámbito es el puramente social. Las esculturas estaban ubicadas únicamente como referencia a los personajes más destacados, por lo que durante estas convulsiones su posición privilegiada sufrió alteraciones, como io evidencia el hecho de no volverse a erigir monumentos escultóricos de aqueIla índole; y en segundo lugar, al disponerse, después de estos acontecimientos, un mayor número de ajuares con elementos vinculados al mundo militar, fenómeno que no acontece en los momentos anteriores en el seno de las

\footnotetext{
- Queremos agradecer a la Dra. Ma Paz García-Gelabert todas y cada una de las sugerencias y correcciones realizadas.
} 
elites, como observamos en la fase antigua de El Oral (SALA, 1996, 20). Así como señala Aranegui (1991, 177-179), después de la destrucción de las esculturas se produce un incremento en el número de enterramientos en los que está presente algún tipo de armamento, siendo cuantificado para Cabezo Lucero en un $61,2 \%$ de las tumbas datadas a finales del siglo IV a.C. Este fenómeno supone, en su opinión, una disminución en la jerarquización del grupo en comparación con el momento anterior o periodo de fundación (500-480 a.C.), en el que la presencia de ajuares militares aparece en un $37,5 \%$ de los enterramientos.

Si los monumentos estaban destinados a ser distintivo de los personajes más destacados, y tras su destrucción se produce una reducción de la jerarquización interna de este sector, entonces estamos admitiendo que la economía de este status social se ha visto afectada por este proceso. ¿O acaso, según este principio, las clases dirigentes de una población concreta no serían más pudientes cuantos más monumentos tuviesen?. Una población con una base económica exclusivamente agropecuaria, sin otro aliciente, no podría hacerse con los servicios de los tan traídos artistas errantes, por eso la destrucción tiene una articulación económica clara. Por todo ello admitimos que si el proceso fue causado por la propia dicotomía social, estamos afirmando que tuvo repercusiones en el ámbito económico. Sirva como ejemplo las consecuencias originadas con la toma de Himera por los cartagineses, como admite Blázquez (1974, 29-31), tras la cita de Diodoro (XIII, 90): "todas estas destrucciones influyeron muy negativamente en la buena prosperidad económica y crearon la miseria".

Descartamos un proceso bélico generalizado ya que éste hubiese significado un atentado contra la totalidad de la población, es decir, contra los poblados, y no contra un elemento tan exclusivo, tan sintomático de un sector económicamente destacado.

De todo este argumento se pretende extraer una idea: la destrucción de las esculturas es, para el historiador, un proceso dialéctico, multidireccional, lo que hace que teorías basadas en una única vía argumentativa carezcan de validez. Se trata en definitiva de un proceso complejo.

\section{HISTORIOGRAFÍA DE LA DESTRUCCIÓN}

Las abundantes teorías propuestas por los historiadores han sido reducidas a ocho variantes, si bien dentro de las líneas generales que las engloban podemos establecer algunas mati- zaciones, o admitir que ciertas teorías como la de Lucas $(1991,197-199)$ no presentan una visión lineal del problema, sino múltiple, o posturas eclécticas como la de García Cano (1991, 313-347). Los modelos teóricos son:

1- Rechazo hacia la ostentación: teoría defendida por Rouillard, (ABAD y SALA, 1991, 156), siendo algo no exclusivo del mundo ibéri$c o$, pues también habría ocurrido algo similar en Grecia en los siglos VI y V a.C.; a este respecto nos dice Plutarco en la Vida de Solón:

“... Realizó el objetivo principal para la salvación y la concordia de la ciudad, que ningún ciudadano fuera rico ni pobre..." (XVI, 2).

"De los demás matrimonios suprimió las dotes y dispuso que la novia aportara tres mantos y un ajuar de poco valor, pero ninguna cosa más". $(\mathrm{XX}, 6)$.

"Y prohibió el sacrificio del buey, enterrar con el cadáver más de tres mantos..." (XXI, 6).

"Es elogiada también la ley de Solón que prohibe hablar mal de los muertos" (XXI, 1).

2- Cambios en las pautas comerciales: para Almagro (1982a, 210) los monumentos están destinados a fomentar los vínculos comerciales de ahí su ubicación en puntos estratégicos (SALA, 1996, 21).

Hacia el 500 a.C., se produce una alteración del comercio entre las zonas costeras del SE., y las regiones mineras de la Andalucía Oriental. Dicho comercio debió comenzar a declinar a medida que se fue centralizando y monopolizando por la presión colonial púnica cuya concreción máxima fue la fundación de Cartago Nova por Asdrúbal (ALMAGRO, 1982b, 185). Esto habría generado cambios dinásticos y con ellos alteraciones en las estructuras de poder, así como enfrentamientos entre los distintos grupos (RUANO, 1987a:58-62) y con éstos la ruina de las esculturas.

Aranegui $(1991,178)$ matiza esta idea, aplicando su hipótesis a la necrópolis de Cabezo Lucero. En este conjunto de poblado y necrópolis encontramos dos momentos. Se caracteriza la primera fase por la presencia de vínculos comerciales con la zona turdetana, planteándose la posibilidad, debido a este motivo, de una fundación por parte de pobladores foráneos para este poblado (ARANEGUI, 1991, 179). En el plano social la principal característica de este momento fundacional (500-480 a.C.), viene significada por una alta jerarquización social. El segundo momento se produce al entrar el mundo ibérico en crisis, Cabezo Lucero gravita, desde 
el punto de vista económico, en ese momento hacia el ámbito de influencias de La Alcudia. Estas mutaciones comerciales originan las destrucciones de los monumentos.

Se ha perdido una situación económicamente favorable, para pasar a otra etapa socialmente más normalizada, y con una menor jerarquización social dentro de las elites, como lo significan los cambios ajuarísticos.

El argumento más favorable a la teoría de ambos autores es la cercanía existente entre la Vía Heraclea y las necrópolis, así como la ubicación de los monumentos turriformes en puntos estratégicos (ALMAGRO, 1982a, 208). Además, debemos tener en consideración el siguiente pasaje de Arriano, en el que se menciona la obligación de los comerciantes de que aparezca en sus transacciones el nombre de un héroe. Se trata así más que de una obligación de un modo de proteger un sector económico clave, al figurar en esos contratos, o bien el nombre de este personaje pseudodivino, o bien el nombre del templo. De este modo, podemos entender cómo este sector comercial, vital, estaba plenamente controlado por las clases dirigentes.

"Encargaba Alejandro en esta carta que se le construyera a Hefestión un templo de héroe en Alejandría (Egipto), uno propiamente en la ciudad, y un segundo templo en la isla de Faros, donde está la torre de la isla, templo que sería de máximas dimensiones y extraordinario por el costo de sus obras. También le encargaba que el templo se denominase Hefestión, nombre que debía inscribirse en los contratos que los comerciantes conviniesen entre sí." (Arriano, Anábasis VII,23,7).

3- Cambios internos: Llobregat $(1966,45)$ admite desconocer qué cambios internos pueden provocar que unas esculturas antes reverenciadas pasen a convertirse en "materiales de derribo". Para Olmos $(1991,30)$ la situación del siglo $\mathrm{V}$ a.C. puede calificarse de crisis social e ideológica, produciendo como efecto inmediato la supuesta reacción iconoclasta.

4- Cambios internos que acaban generando revoluciones sociales: Aparicio $(1977,30)$ argumenta posibles causas sociales y políticas de raíces profundas, o amplia base popular, quizás apoyadas por fuerzas externas (1982, 45), que producirían una revolución social destinada a eliminar las ideas representadas en los monumentos, y que habrian sido importadas por una elite concreta y dominante.
Asociada a esta argumentación, pero admitiendo explícitamente la existencia de posibles cambios religiosos, Lucas (1991, 197199) defiende una reacción indígena contra los elementos traídos de fuera; los monumentos representarían pues, un intento de legitimar el poder por parte de las elites al más puro estilo oriental. Coincidiendo con esta destrucción en el tránsito de los siglos V al IV a.C., se produce el auge de las construcciones templarias y de las esculturas no destinadas a las necrópolis. A ello se uniría nuevos ritos como libaciones y aras funerarias, acordes con las nuevas aristocracias guerreras, cuyos rituales de enterramiento estarían de acuerdo con los decretos contra los excesos; por lo tanto estaríamos ante unos cambios socioculturales.

Esta revuelta social tiene para Uroz (recopilado por RUANO, 1987b, 114) un claro contenido político y a la vez religioso, lo que no parece tan evidente son los resultados, pues no precisa si se produjo la erradicación de estos poderes. Situación semejante parece haberse vivido con el ataque de los escitas a los persas, de modo que podemos establecer, con las debidas reservas, el siguiente paralelo mediante el pasaje de Heródoto (Historias IV, 127, 1-3):

"A este mensaje, el rey de los escitas, ldantirso, respondió como sigue: "Mi actitud, persa, responde al siguiente criterio: hasta la fecha, yo jamás he huido por temor ante hombre alguno $y$, en estos momentos, tampoco estoy huyendo ante ti. Además, en la actualidad no estoy haciendo algo distinto a lo que de ordinario solía hacer en tiempo de paz. Y también te voy a explicar por qué razón no te presento batalla sin pérdida de tiempo: nosotros no tenemos ciudades ni tierras cultivadas que podrían inducirnos, por temor a que fuesen tomadas o devastadas, a trabar de inmediato combate con vosotros para defenderlas. Ahora bien, si hay que llegar a toda costa a ese extremo cuanto antes, nosotros, como es natural, tenemos tumbas de nuestros antepasados. Así que, venga, descubridlas e intentar violarlas y entonces sabréis si lucharemos contra vosotros en defensa de las tumbas o si vamos a seguir negándonos a presentar batalla. Pero, hasta ese momento, si no nos viene en gana, no trabaremos combate contigo".

Esta teoría defendida principalmente por Aparicio (1982, 33-46), adquiere una mayor consistencia, sobre todo a partir de la hipótesis que recientemente se ha planteado y que defiende que en las necrópolis sólo se enterrarían determinados sectores de la población 
(SÁNCHEZ y QUESADA, 1991, 374; LUCAS, 1991, 192-193). Tras esta revolución social, la necrópolis pasaría a ser ocupada por capas más amplias de la comunidad, lo que explicaría la falta de un hiatus (ARANEGUI, 1991, 176), y la mayor equidad en los ajuares funerarios; siendo, por tanto, un síntoma de que el movimiento causante de la destrucción de las esculturas en las necrópolis, "puede deberse a una especie de revolución social de amplia base popular" (APARICIO, 1982, 45) y tiene como resultado la apropiación de un privilegio por parte de un sector más variado de la sociedad antes exclusivo de las elites.

5- Acciones bélicas: mientras que para Blanco (1986, 3-8) estas acciones son comunes en la totalidad del ámbito mediterráneo, y tienen como fin tanto obtener productos para el pillaje, como minar la moral de los ejércitos, para Lillo y Serrano $(1989,79)$ se deben a acciones entre los pueblos rivales, cuya finalidad es intentar borrar los valores ideológicos y espirituales.

Tenemos documentados ejemplos, bien es cierto que geográficamente muy lejanos al caso aquí tratado, en los que se nos mencionan cómo la rivalidad entre los pueblos hace que templos, tumbas y demás elementos sacros sean destruidos:

"Himera fue arrasada por los cartagineses, y a continuación los templos y las casas de Agrigento". (Diodoro XIII, 90).

"Mira bien lo que hoy te mando: voy a echar delante de ti al amorreo, al cananeo, al hitita, al fereceo, al heveo, y al jebuseo. No hagas pacto alguno con los habitantes de la tierra en la que vas a entrar, para que no te hagan caer en sus redes. Antes bien, destruir sus altares, romped sus estelas, destrozar sus cipos". (Exodo 34, 11-13).

A simple vista esta teoría estaría en consonancia con la destrucción que poblados, Bastida de les Alcuses, Mola de Torro y El Puig, entre otros, padecen en ese mismo momento (LLOBREGAT, 1972, 34-58). Por el contrario parece ser, que el final de éstos no debió estar causado por las acciones bélicas de grupos rivales, ya que el arrasamiento de estos poblados no está en consonancia con el poder destructivo que los pueblos iberos tenían en el siglo IV a.C. (TARRADELL, 1961, 19). Asimismo debemos tener presente que existe un matiz diferenciador entre poblados y necrópolis. Mien- tras que aquéllos aparecen destruidos y no vuelven a ser utilizados, se generan poblados ex novo, las necrópolis sufren un desbaratamiento pero no un abandono, sino que son utilizadas, parece ser con un proceso de continuidad.

6- Acciones púnicas y cartaginesas: Esta visión historiográfica evoluciona en el transcurso del tiempo. Fernández Avilés (1941, 33) responsabiliza del fenómeno bien a las tropas de Aníbal, bien a las primeras legiones romanas. Visión cronológica no compartida por Nieto (1940,191-196), pues según él, el arrasamiento de las necrópolis se produce en época de Amílcar.

También Pla (1975, 737), se adhiere a la hipótesis original de Fernández Avilés, si bien es más ambiguo en la explicación, pues simplemente admite como artífices del proceso a los cartagineses.

Postura semejante es la defendida por Blázquez (1962, 189-195), quien aboga por las razzias lusitanas y celtibéricas, apoyadas éstas por los púnicos, en un claro intento de cubrir las necesidades económicas y demostrando de la misma forma la falta de temor hacia los templos y demás construcciones sacras.

De cualquier modo esta teoría parece poco convincente, habida cuenta de la existencia de esculturas destruidas y datadas ya antes de la invasión cartaginesa (QUESADA, $1989,23)$. Si bien es cierto que esta argumentación es sólo aplicada por Quesada para la necrópolis de Cabecico del Tesoro, es fácilmente extrapolable al resto del territorio analizado. Además, como hemos visto en la cita de Diodoro en XII, 90, la rivalidad entre los dos pueblos supone la destrucción de la ciudad, pero más dificultosa resulta admitir la posibilidad de que sea toda una zona geográfica la que aparezca destruida, como ocurre en el caso del corredor levantino.

7- Destrucción como elemento de duelo: según Ramos Fernández (1988, 374), formaría parte del ritual de enterramiento, en un claro intento de honrar al difunto.

Si esta argumentación es correcta, la praxis debe ser introducida dentro de lo que Cuadrado $(1985,185-203)$ ha denominado rito de enterramiento destructivo. Dos son los argumentos que podemos poner en contra de esta teoría:

- Si esta es práctica habitual, no debe haber motivo para el cambio; máxime teniendo 
en cuenta que la religión es el elemento más arraigado en una cultura. La incapacidad para la realización de estas manifestaciones, por causas económicas, en un momento concreto, justificaría su progresiva desaparición en la necrópolis correspondiente, pero nunca el final violento a lo largo de todo el litoral peninsular.

- Cerámicas, falcatas, y otras armas son destruidas intencionadamente, o más correctamente, son dobladas e inutilizadas voluntariamente, como elementos propios del ritual, pero no sufren traslado, ni mucho menos son empleadas para entibar urnas funerarias, como ocurre con los fragmentos escultóricos. Si estuviesen depositados, como sugiere Ramos $(1988,373)$ para formar parte del ajuar, primero se colocaría el elemento más significativo de la pieza, por ejemplo una paloma o granada como símbolo a Tanit, y no un fragmento cualquiera como se produce; $y$ en segundo lugar dicho fragmento ocuparía una posición estratégica dentro de la disposición del ajuar, pero nunca sería un elemento sustentante de la urna.

8- García Cano (1991, 333): no admite una destrucción tan sistemática de las esculturas, como para que no exista resto alguno. En algunos de los casos estos elementos pudieron caerse por las luchas tribales, y cambios en la estructuras sociales y religiosas de un mundo ya muy atomizado.

9- Destrucción no violenta: según Chapa (1993, 193), los cambios económicos crean nuevas interacciones territoriales. Desaparece así, $y$ juntamente con los grandes poderes centralizados, el gusto por las grandes obras escultóricas. Estas modificaciones no significaron acciones violentas contra las construcciones realizadas con anterioridad, pero sí el abandono progresivo, y como consecuencia de éste y de carencias en las infraestructuras, el progresivo desmoronamiento de los monumentos.

\section{ESCULTURA Y NECRÓPOLIS}

El desconocimiento que tenemos sobre los siglos VI y V a.C., así como el estado en el que han aparecido las necrópolis, nos priva de una visión evolutiva, tanto de la propia arqueología de la muerte como de los conocimientos históricos, económicos y sociales que podríamos establecer a partir del estudio conjunto de estos cementerios ibéricos. Bien es cierto que los recientes avances efectuados en el ámbito de la arquitectura y escultura (CASTELO, 1994, 139-171), nos ponen de manifiesto que el panorama de las necrópolis ibéricas no debía estar cerrado a los dos monumentos tradicionales, pilares-estela y turriformes. Han sido estos avances, y los intentos de establecer los orígenes e influencias del arte ibérico, los que han negado la existencia de dos elementos básicos en cualquier construcción de tipo sacro. Son en definitiva el temenos y el dromos, recuperando para el análisis de este segundo elemento la hipótesis enunciada por el profesor Llobregat (1972, 162).

Ninguna prueba existe en contra del argumento de Almagro (1982a, 208-209) en el que se defiende a los monumentos turriformes como verdaderos generadores de las necrópolis y ocupando una posición estratégica en los cruces de los caminos o presidiendo el lugar central de aquélla. A partir de aquí se generarán unos enterramientos auxiliares propiciados seguramente como consecuencia de la fides ibérica. Por consiguiente el elemento turriforme estaría rodeado de otros enterramientos, evidentemente mucho más pobres, ya en estructuras, ya en ajuares, como debería corresponder a la clientela del jefe redistributivo. Entonces, puesto que el territorio que conforman las necrópolis no está acotado por muro alguno (GARCÍA HUERTA, 1995:69), cabe preguntarse: ¿dónde está el límite de éstas?, ¿cuáles son los elementos que precintan el terreno a ocupar?. Quizás a la tan traída función apotropaica de los pilares-estela haya que añadirle un marcado carácter delimitador, de modo que un extraño por el simple hecho de presenciar estos monumentos arquitectónicos y escultóricos, concibiese estar ante un evidente lugar sagrado.

Si la hipótesis aquí apuntada es cierta, habría que ver estos pilares-estela como posibles profilácticos del elemento central, es decir del monumento turriforme. De este modo quedaría explicada la existencia de una doble jerarquización, por una parte una preeminencia territorial del monumento turriforme frente al pilar-estela, y una posición más elevada de aquél sobre éste, en la vertiente arquitectónica, y por tanto un status social superior del personaje enterrado o representado en el monumento turriforme (CHAPA, 1986, 235), que no de los defendidos por las esculturas existentes en los pilares-estela. Una buena prueba de ello es la certificación de Castelo $(1994,158)$ en la que advierte que los animales exóticos son pronto sustituidos de los pilares-estela por otros de 
naturaleza más común en la Península Ibérica, pasando a formar parte aquéllos, los animales exóticos, de otros monumentos de mayor envergadura, como debe corresponder a personajes de tipo áulico (ALMAGRO, 1982a, 209).

Prueba de ello y, como se aprecia en el índice de restos, los casos existentes de pilares-estela con cronología ya del siglo V a.C., La Alcudia, Cabecico del Tesoro, Coimbra (CASTELO, 1994), el Prado (GARCÍA CANO, 1991) y Corral de Saus, no presentan en ninguno de los casos una coronación con animales exóticos.

Por tanto a la función apotropaica, a la que nada se puede negar por la simbología de los animales allí representados, unimos una doble delimitación tanto de la propia sepultura que coronan, como del conjunto de la necrópolis. La principal prueba que avala esta hipótesis es la existencia de superposiciones, como las del Cabecico del Tesoro y El Cigarralejo (SÁNCHEZ y QUESADA, 1991, 360), que ponen de manifiesto el carácter sacro de los territorios, así como la posible existencia de algún elemento de delimitación (GARCÍA HUERTA, $1995,69)$ impidiendo la expansión. Por consiguiente, en caso de una posible saturación del territorio a ocupar, la necrópolis se expandiría previa nivelación, (LUCAS, 1991, 195) verticalmente, como ocurre en Pozo Moro, Los Villares o El Cigarralejo, pero no horizontalmente, lo que pone de manifiesto la consideración especial que tienen los territorios ocupado por los enterramientos. Junto con todo ello constatamos en construcciones posteriores, como la de El Parque de Elche, la existencia de verdaderos témenos (RAMOS FERNÁNDEZ, 1988, 370), indicando que estamos ante una forma arquitectónica familiar para el íbero.

Por contra, el principal argumento que se puede oponer a esta hipótesis es la inexistencia en las necrópolis ibéricas del litoral levantino de algunos monumentos turriformes, a lo que podemos combatir argumentando bien la propia destrucción de las esculturas.

"Sabemos, por tanto, que las esculturas formaban parte de la guarda decorativa de los accesos a algún lugar. Pero la presencia de un elevado número de las mismas en Rojales y su posición en pie y echada, me ha hecho pensar si nos encontramos con un ejemplo de vía sacra o dromos flanqueado por los animales guardadores del lugar santo. El concepto, de vieja raigambre oriental y mediterránea, que se ha repetido en otras culturas que no tienen nada que ver con las de esta área del mundo, parece, por tanto tan universal que no sería extraño suponerlo en lberia, donde además lo abona la viejísima tradición de relaciones y de cultos orientales ..." (LLOBREGAT, 1972, 162-163).

¿Por qué debe existir un dromos en una necrópolis?, y ¿a qué punto final conduce?

Ambas preguntas adquieren respuesta tras certificar la existencia o bien de paramentos con nichos-hornacinas, donde parece ser que estarían representadas las damas de la fecundidad (CASTELO, 1990, 39), o bien conformando éstas simples bustos. La hipótesis de trabajo del profesor Llobregat sugiere que las esculturas de estos dioses o semidioses estarían flanqueadas por animales, formando un dromos o avenida y desempeñando éstos una nueva función apotropaica, de la misma forma que ocurría en Egipto a la puerta de los templos (CHAPA, 1986, 139).

Apoyando esta línea argumentativa nos encontramos con la representación del bóvido de Barcelona (vide índice de restos), que parece ser, pese a tener uno de los costados sin apenas labrado, no desempeña función sustentante, como sillar de esquina, dentro de un monumento turriforme, sino que sería el guardián de una supuesta dama sedente, que apoyaría sus brazos sobre los lomos de sendos animales (SANMARTí, 1987, 265), quizás siendo el punto final de una alineación de estas representaciones.

Paralelamente a estos dos ejemplos antes citados, debemos señalar la existencia de plataformas, escalonadas o no, sobre las que se ubican esculturas zoomorfas con una clara función defensiva o apotropaica, como son los casos "p", "c", "b", "e", y "g", documentadas en Cabezo Lucero (ARANEGUI, 1993, 69-72). En ellas se hace patente la idea de un altar como final de una avenida, de unos tres metros de anchura, y flanqueada por estas plataformas, cuya función, en algunos de los casos, debido al estado de conservación, no ha sido aclarada. Debemos tener en cuenta que estas plataformas no pueden ser identificadas con pilaresestela, pues su altura no es propia de éstas (ARANEGUI, 1993, 75), pero por el contrario, y como aquéllos, sí estaban coronadas por animales.

Un dato más a favor de la hipótesis de Llobregat lo aporta las mayores dimensiones de un felino, también de Cabezo Lucero, que hacen pensar que pudo ser el remate de un pilarestela, tratándose, de esta forma, de un monumento diferente y con una función desigual, como es la de protección de la tumba, con res- 
pecto a los animales representados en las plataformas antes vistas. Por si esto fuese poco según los antiguos excavadores los animales, bóvidos en su mayoría, habrían aparecido conformando dos filas, y no sólo eso sino que "el hallazgo de un brazo de trono sugiere la existencia de al menos una dama sedente" (CASTELO, 1994, 156), quizás como punto final de una alineación.

En consecuencia, pese a no poder generalizar la existencia de un dromos en la totalidad de las necrópolis del litoral levantino, puede ser Cabezo Lucero la pieza que nos ponga sobre aviso ante la posible existencia de esta avenida en las necrópolis, dando de este modo una función a las esculturas que obligaría a no considerarlas exclusivamente como protectoras de una sola sepultura. Así la presencia de un altar aislado y un plinto, cuya morfología difiere de los pilares-estela, en Los Nietos (CASTELO, 1994, 154), pueden ser el punto final al que conducen estas alineaciones.

La existencia de una doble altura de elementos arquitectónicos delimita claramente la función de éstos dentro de la necrópolis, por un lado los de dimensiones más reducidas encauzarían el camino bien hacia alguna especie de altar, donde se llevarían a cabo los ritos, bien hacia la representación de alguna divinidad, o incluso hacia el monumento turriforme. En cambio la mayor altura de los pilares-estela proporcionan la delimitación de la totalidad de la necrópolis, consiguiendo de esta forma una jerarquización del espacio, en consonancia con una sociedad jerarquizada; es, en definitiva, la unión entre el significante y el significado. Se genera así un espacio central dominado por el monumento turriforme, o personaje de mayor prestigio, y unos enterramientos secundarios, los pilares-estela, con una ubicación alrededor de aquél.

\section{ESCULTURAS ZOOMORFAS VS. ANTRO- POMORFAS}

Dentro de los dos grandes grupos que conforman las esculturas, son las zoomorfas las que aparecen destruidas más comúnmente. El motivo es simple: éstas son las más abundantes en esta zona, ya que las antropomorfas estarían reservadas a la realización de monumentos de tipo heroa, o a la escasa presencia de bustos (dos en índice de restos) y hornacinas, es decir, a la exaltación de un personaje. Por el contrario las funciones de las esculturas zoomorfas serían bastantes más laxas, desde transportar al individuo al Más Allá, como la de ser animal guardián de los monumentos, acompañar al difunto en sus actividades en el mundo de ultratumba, ser elementos coronantes, etc.

El gráfico número 1 resulta bastante preciso a este respecto, un $66 \%$ de las representaciones del área levantina son representaciones animalísticas. De éstas el $41 \%$ (vide gráfico número 2) son representaciones de toros. El grupo mayoritario lo conforman pues, animales con una clara presencia en el ámbito ibérico, un elemento en definitiva altamente familiar dentro de la vida cotidiana de los íberos. Es, por tanto, la constatación de la idea defendida por Castelo $(1994,158)$ en la que argumenta el paso de los animales fabulosos a las construcciones más pudientes, monumentos turriformes, estando dispuestos los animales más familiares para el ibero en los pilares-estela.

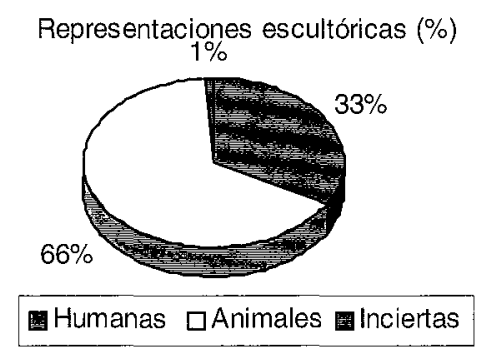

Gráfico 1

Como apreciamos en la tabla cronológica, ya a lo largo del siglo $\mathrm{V}$ a.C., los monumentos turriformes de El Parque de Elche, cuentan con representaciones de esfinges, - lo mismo ocurre en el monumento de Bocairente, de cronología no especificada, mientras que en el caso de los pilares-estela, no aparece ningún animal exótico, si exceptuamos las presencia de leones

A pesar de que este animal no estaba presente dentro de la geografía ibérica, el gráfico número 2 demuestra la gran difusión de éste, y

Esculturas zoomorfas (\%)
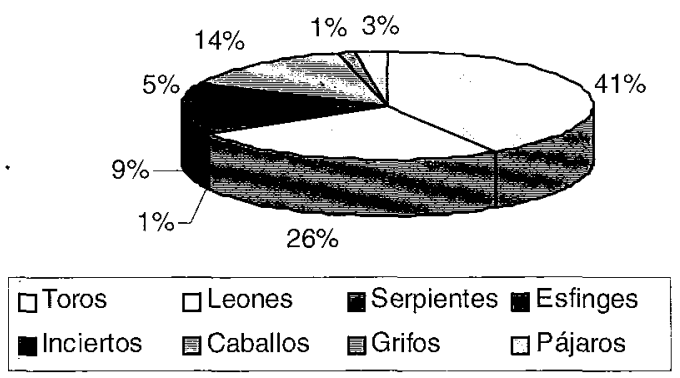

Gráfico 2 
su importancia dentro del ámbito peninsular mediterráneo, conformando el $26 \%$ de las representaciones.

La significación del león es, en opinión de Chapa $(1986,141)$, por un lado la de ser guardián de la tumba, y en segundo término, la de relacionar el difunto al que el león protege, con un personaje de alto valor militar y diestro en el manejo de las armas. Analizados los porcentajes y esta argumentación la pregunta que se desprende de este estudio es: ¿cuáles son los motivos por los que aparecen unos y no otros?.

Si lo que se pretende es la admiración de las cualidades personales del individuo, parece lógico que deberían ser las figuras de los leones las más abundantes, y sin embargo lo son las de los toros, es decir son los animales más comunes los más afirmados en los monumentos. Por ello Chapa (1986, 151-156) atribuye a los toros de su "grupo A", una doble función:

1- La representada por el bóvido en sí, la de ser propiciatorio de la fecundidad, de ahí la representación de los órganos genitales.

2- La funcionalidad propia del felino, la agresividad, de ahí su gesto amenazador y poco naturalista (CHAPA, 1986, 156). Un dato que corrobora esta hipótesis es la importancia de los elementos simbólicos e identificativos, entendiendo por tales las defensas en la mayoría de los animales. La importancia de éstos queda claramente reflejada, al estar en muchos de los casos estudiados, aunque no siempre (ARANEGUI, 1993, 83), realizados en un material substancialmente diferente al resto de la pieza escultórica, esto es, no en caliza o arenisca local blanda y fácil de trabajar (BENDALA, 1990, 148), sino que en algunas representaciones se han practicado unos orificios que permiten introducir las defensas del animal (CHAPA, 1986, 226), realizadas en otro material más resistente; hipótesis contrastada en los ejemplos de Cabezo Lucero (ARANEGUI, 1993, 71, 83) o el de El Parque de Elche (CHAPA, 1986, 90), o el de La Carencia (LLOBREGAT, 1975).

A pesar de este carácter polifuncional, y su aspecto amenazador, el toro no tiene, en opinión de Chapa, un carácter apotropaico (CHAPA, 1986, 156).

Realmente tenemos garantizada la presencia del toro como animal propiciatorio de vida, recordemos que es la primera cualidad atribuida por Chapa, y éste debió ser un elemento muy importante dentro de las religiones en el mundo antiguo (GARCÍA-GELABERT y BLÁZQUEZ, 1997, 418-420).

\section{¿DESTRUCCIONES SELECTIVAS?}

¿Cuántos golpes hacen falta para destruir una escultura?. La respuesta es sencilla, depende del tamaño de la obra, de las dimensiones del objeto percutor, de la fuerza del golpe, y de la consistencia del material. Como vimos líneas arriba, el material de las esculturas suele ser caliza o arenisca local muy endeble, por tanto, uno o dos golpes certeros bastarían para desmoronar una escultura, si realmente es esto 10 que se pretende. Como ejemplo citaremos el guerrero de La Alcudia (RAMOS FOLQUÉS, 1950, fig. 1), que aparece conformando un casi perfecto triángulo equilátero, claro testimonio de que ha sufrido al menos cinco certeros impactos en puntos diferentes: uno en la cabeza, dos $y$ tres en los hombros, un cuarto en la cadera, y el quinto en el costado izquierdo.

El arrasamiento de esta escultura es claramente perfeccionista, hasta el punto que el guerrero ha perdido todos sus puntos vitales, la cabeza, los brazos y las piernas; la funcionalidad del guerrero es así nula. El personaje representado se ha visto desposeído de todas sus cualidades personales. Estamos ante un guerrero, paradójicamente, incapaz de defenderse.

Extraer conclusiones exclusivamente a partir de esta obra es muy peligroso, porque este mismo guerrero podría haberse arruinado tras una caída, pero una vez más Chapa nos pone sobre aviso a este respecto y afirma que en el $50 \%$ de los casos los toros aparecen sin cabeza y en un $40 \%$ del total $\sin$ los cuartos traseros (CHAPA, 1985, 795-803). Mientras para el caso de las esfinges nos dice:

"El segundo problema se centra en la fragmentación del material. Son contadísimas aquellas piezas que conservan la cabeza y las patas, y normalmente el único elemento que sirve para su identificación son las alas" (CHAPA, 1980, 309).

Como ejemplos de la destrucción de estos elementos simbólicos, podemos citar los ejemplos de las plataformas "b" $\mathrm{y}$ "e" de Cabezo Lucero (ARANEGUI, 1991, 172), o el toro de Benimassot (CORTELL, 1989), que ha perdido cuernos, cuartos traseros y genitales, el de BaIones (LLOBREGAT, 1966), el de Villajoyosa (LLOBREGAT, 1974), o el de Monforte del Cid (ALMAGRO, y RAMOS FERNÁNDEZ, 1986).

Por consiguiente, mediante este ataque, se ha producido la ruptura de los puntos anatómicos más cargados de significación, de esta forma, según la hipótesis defendida por Chapa, 
el arrasamiento de los cuartos traseros lleva implícito la eliminación de los órganos reproductores, lo que hace que el binomio toro fertilidad haya perdido todo su sentido. Del mismo modo la ruptura de las cuernas supone la pérdida de todo poder defensivo del animal, de modo que la sepultura y/o dromos quedan totalmente carentes de protección. La funcionalidad del toro es por tanto, y como ocurría en el caso del guerrero de La Alcudia, nula. El semblante amenazador que debería poseer ya no es tal tras el arrasamiento que ha padecido. El bóvido ya no puede ni propiciar, ni defender vida (Cf. ALMAGRO y RAMOS, 1986, lams. 4a, 5a).

Rastreemos ahora la ruptura que sufren las esculturas de los leones. Parece evidente en estas representaciones el carácter apotropaico, es por tanto lógico que si la hipótesis apuntada en estas líneas es correcta, éstos, los leones, deben perder sus maxilares, sus fauces, en definitiva. Se cumple esta condición, al menos en el caso del león de El Cigarralejo (CUADRADO, 1984, 260), al que le falta toda la cara, todo el elemento defensivo, todos los atributos que le otorgan fiereza. De la misma necrópolis es la escultura, también león, de la que sólo tenemos segura constancia por la existencia de su aparato defensivo, mostrando así que se ha querido separar las fauces del resto del cuerpo (CUADRADO, 1984, 261). Ejemplo similar lo tenemos en el de Lloma del Galbis (LLOBREGAT, 1966), al que le falta el hocico, o en el de Vizcarra que ha sufrido ataque semejante (LLOBREGAT, 1966).

El mismo esquema lo volvemos a encontrar en las esfinges, como la del Cabecico del Tesoro, en estado acéfalo y áptero (CHAPA, 1980 , 312). Habiendo perdido tanto el carácter de defensora, como el de medio transmisor del difunto hacia el Más Allá (CHAPA, 1980, 329). Este parece ser el sentido de las esfinges, demostrado por el del Parque de Tráfico de Elche (CHAPA, 1980, 316, lam. 4), ya que transporta a dos personajes femeninos, y a los que no puede defender puesto que ha perdido sus fauces. Igual ocurre con la esfinge de Agost (CHAPA, 1986, 116; RAMOS FERNÁNDEZ, 1988), hoy acéfala.

Estos tres grupos animalísticos han perdido en este proceso de destrucción los atributos que les confería su primera funcionalidad, la de la protección del difunto.

Vistos tres de los subgrupos zoomorfos, el paso siguiente es ver sobre qué elementos actuó la destrucción en las esculturas antropomorfas, estableciendo si la hipótesis anun- ciada en los tres apartados anteriores se mantiene o no en este segundo grupo.

Debemos comenzar dejando constancia que el carácter apotropaico, tan defendido en estas líneas, no se aprecia de forma tan evidente en representaciones, que como los bustos, no muestran un semblante fiero presente en la estatuaria animalística. Admitiremos por tanto como evidente que en el caso de las esculturas antropomorfas se pretende la exaltación de las cualidades personales del individuo. En caso de tratarse de divinidades o personajes semidivinos, son los rasgos faciales los que nos conducen a la identificación de la deidad, o bien los rasgos más representativos de los dioses, como el rayo en el caso de Zeus.

Dos son los interrogantes que desmienten o afirman esta hipótesis:

1. ¿Atenta la destrucción contra los rasgos faciales, o los elementos más representativos que nos permiten identificar a esas divinidades?.

2. ¿Cuáles son las pretensiones de estas destrucciones?.

Veamos algunos ejemplos que informen a este respecto. Como primer ejemplos citamos el monumento de Alcoy (ALMAGRO, 1982b). Dejando de lado el hecho de que sólo se conserven dos de las supuestas cuatro damitas, en una de ellas se destruyó la cabeza al completo, mientras que en la segunda de las representaciones el personaje carece de mandíbula. Por si esto fuese poco, en uno de los dos ejemplos no conservamos uno de los dos objetos iconográficos de la pieza, sí el aulos, pero no el elemento posiblemente sostenido en la mano derecha, pudiendo tratarse, por inferencias de otros paralelos peninsulares, bien de una granada, bien de una paloma, quizás como atributo de Astarté.

En el caso de El Corral de Saus (ALMAGRO, 1987), de las cuatro damas sólo una conserva el elemento simbólico, apareciendo éste en la mano derecha. A pesar de que en este caso no se ha destruido el símbolo iconográfico, sí es cierto que la pieza aparece decapitada (APARICIO, 1982, 35). Caso semejante ocurre en Pino Hermoso (ALMAGRO y RUBIO, 1980), donde un personaje semidivino, o al menos alado ha sido guillotinado. Del jinete que monta el daimon conocemos su existencia por una de las piernas, siendo el único resto. La función potencial de la esfinge como medio de transporte ha quedado arruinada. El personaje central ha perdido el privilegio de conducir un ser mitológico en su tránsito hacia el Más Allá. 
La necrópolis de El Cigarralejo presenta dos hornacinas en las que falta tanto la mano como el objeto que mantenía ésta, identificado como una paloma, guardando relación con la diosa Astarté (CASTELO, 1990, 36-39). Deducimos así la ruptura del elemento que identificaría a la divinidad.

Cortell $(1989,545)$ nos informa de la existencia de una dama acéfala en Benimassot, careciendo además de pies y de las manos, donde quizás albergase el atributo característico.

Y como último ejemplo de estas destrucciones dirigidas en Vizcarra aparece una dama sedente sin cabeza (LLOBREGAT, 1966).

Comenzamos admitiendo los peligros que suponía levantar una hipótesis a partir de la escultura del guerrero de La Alcudia. En cambio una vez vistos los ejemplos de los leones, toros, esfinges, bustos, damas, y las referencias de Chapa, podemos comenzar a pensar, si no debemos ver la destrucción como un proceso que parece atentar contra los elementos más representativos de las esculturas, una agresión a "los puntos vitales de la escultura".

Bien es cierto que en todos los casos analizados, la supuesta ruptura planificada se lleva a cabo contra los elementos más frágiles. Cabezas, cuernos, rostros, o elementos labrados con relativa minuciosidad (granadas o palomas), y que fácilmente éstos podrían haberse desprendido tras una simple caída, (CHAPA, 1993, 185195) Parece inverosímil que esto haya ocurrido en la totalidad de los casos planteados anteriormente, aunque bien pudiese haber sucedido en algunos de estos monumentos.

Por otra parte tradicionalmente la historiografía ha venido tratando de ensañamiento en el proceso de destrucción. Sin embargo, tal vez debamos replantearnos estos términos y no hablar de ensañamiento, sino de destrucciones dirigidas hacia unos elementos concretos del conjunto, aunque efectivamente, en alguno de los casos, las esculturas son machacadas con toda precisión, hasta el punto de no poder atribuirse a la especie a la que pertenecen (vide indice de restos).

\section{CRONOLOGÍA}

Poco es lo que podemos argumentar sobre este aspecto que la bibliografía anterior no haya defendido. Carecemos de conocimientos para fechar los momentos de las destrucciones, ya que como tradicionaimente se ha manteni- do, las esculturas han aparecido normalmente fuera de sus contextos, y desempeñando otras funciones, como la de entibar urnas.

Son dos los datos que nos permiten enmarcar, muy a grandes rasgos, la destrucción o destrucciones de la estatuaria:

1-Los momentos de erección de los monumentos, empleando para tal delimitación temporal tanto los aspectos estilísticos, como el empleo de determinados elementos constructivos, como por ejemplo las grapas.

El monumento del Corral de Saus, según criterios estilísticos puede ser datado en el siglo VI a.C. (ALMAGRO, 1982b, 183) pudiendo considerarse esta fecha como la más temprana de cuantos monumentos ibéricos aquí estudiados se crearon. Con una cronología similar aparecen los restos de Agua Salada, Los Nietos, El Arenero de Vinalopó, La Alcudia, y El Prado (CASTELO, 1994, 146), todos ellos con cronología de fines del siglo VI o principios del V a.C.

Otorgando mayor precisión y por criterios puramente estilisticos podemos datar los toros del "tipo B" de Chapa, echados y esquemáticos, en el tránsito del siglo VI al V a.C.; siendo posteriores los pertenecientes al "grupo A", más realistas ya como propios del siglo IV a.C. (CHAPA, 1985, 777).

Mediante estas dataciones estamos en condiciones de admitir la presencia de un arte escultórico ibérico, al menos, ya a fines del siglo VI a.C. Arte que pervive, con seguridad, hasta la segunda mitad del siglo IV a.C., o inicios del siglo III a.C., como lo evidencia la utilización de grapas para unir varias piezas en el monumento de Pino Hermoso (ALMAGRO y RUBIO, 1980, 350). Además los ejemplos de La Carencia (LLOBREGAT, 1975) y Villajoyosa (LLOBREGAT, 1974) presentan una cronología similar que no va más allá de la transición entre los siglos IV-III a.C. Los valores máximos están representados a partir de las dataciones de $\mathrm{La}$ Albufereta, en el último tercio del siglo III a.C. (FIGUERAS, 1946, 318), lo mismo que las representaciones de Coimbra del Barranco Ancho (GARCÍA CANO, 1994, 183). Estos ejemplos permiten pues, hablar de una estatuaria ibérica con una vivencia de al menos tres siglos.

2- La reutilización de los fragmentos escultóricos. Según lo expuesto con anterioridad podríamos pensar que el proceso de la destrucción debería comenzar en un momento posterior a la fecha dada para los restos más recientes. Esto parece ser después del 350-325 a.C., espacio temporal en el que se crean las esculturas de Coimbra del Barranco Ancho 
(GARCÍA CANO, 1994,183). Sin embargo el problema radica en la existencia de monumentos ya reutilizados y por tanto destruidos y carentes de valor religioso, en un periodo anterior a la creación de las esculturas de Coimbra, como son el caso de las hornacinas del Cigarralejo, produciéndose su reutilización a partir del 425 a.C. (CASTELO, 1990, 40).

Expresado de otro modo, mientras en una necrópolis se mantiene el arte escultórico, se continúan levantando monumentos, en otras y en ese mismo periodo, las esculturas ya han sido destruidas y reutilizadas, es decir, han perdido ya su significación religiosa.

Debemos comenzar a admitir que no estamos ante un fenómeno simultáneo, puesto que mientras en unas necrópolis las esculturas han perdido su significación, en otros espacios su simbolismo pervive, y como tal continúan creándose monumentos. Sirva como ejemplo el toro de La Albufereta del siglo III a.C. (LLOBREGAT, 1974, 342).

Lo que parece evidente es que el grueso de las reutilizaciones se inicia en el momento de transición del siglo $\mathrm{V}$ al IV a.C. Por lo que sólo podemos puntualizar que la destrucción se produjo, en líneas generales, en algún momento del siglo $\mathrm{V}$ a.C.

Por el contrario somos de la opinión, a tenor de lo expuesto anteriormente, de no hablar de destrucción, sino de destrucciones desde las más tempranas, que parecen ser las de El Cigarralejo (antes del 425 a.C.), teniendo su cénit desde el tránsito del siglo $\mathrm{V}$ al IV a.C., e incluso durante este último. Así lo demuestra la asociación entre los restos escultóricos reutilizados y cerámica ática de barniz negro y precampaniense, con cronologías éstas del primer tercio del siglo IV a.C., y siendo ejemplos: Agua Salada (LILLO y SERRANO, 1989), Cabecico del Tesoro (CUADRADO, 1987), Los Nietos (ALMAGRO y CRUZ, 1982), o la Bastida con cronología de destrucción, en este caso, de un poblado, entre el 340-330 a.C. (PLA, 1975, 737).

Admitimos por tanto que el proceso de la destrucción es un movimiento discontinuo, no simultáneo.

\section{CONCLUSIONES}

Hemos intentado plantear en este estudio el estado de la cuestión, así como algunos puntos de revisión, sobre este interesante tema. A pesar de todo el problema sigue siendo uno de los muchos interrogantes que plantea la Cultura lbérica.

Se ha pretendido demostrar cómo el paisaje de las necrópolis no debe ser una línea tan cerrada como hasta hoy teníamos asumido.

En segundo término hemos anunciado que las destrucciones de las esculturas, no supone una eclosión simultánea, y fugaz, un fenómeno que aparece y desaparece en un brevísimo espacio de tiempo, sino que estamos ante unos ataques en unos momentos concretos, que pueden distar de unas zonas a otras incluso dos siglos de diferencia. Aquí radica la importancia de las fuentes literarias, pues todas ellas tienen en común un factor fundamental, todas y cada una de éstas se refieren a un lugar concreto, al arrasamiento de un templo en una única ciudad, a las tumbas de unos ciudadanos precisos, pero en ningún caso se nos habla del arrasamiento de una amplia zona geográfica, como fue el caso de la Península Ibérica, desde Mogente a Oretania.

En último lugar se ha intentado demostrar que este ataque es un hecho multivariante, con repercusiones económicas, sociales, políticas y religiosas. Fenómeno del que seguimos sin conocer las causas de sus inicjos, pudiendo diferir éstos de una zona a otra, pero evidentemente las destrucciones tienen un claro contenido religioso, de ahi la eliminación de los que hemos venido en llamar los elementos simbólicos; pero presenta, también, unas connotaciones sociales, políticas y económicas claras, como son la posterior reducción en la jerarquía entre los diversos grupos sociales, y la inexistencia de nuevos elementos visuales claramente identificables con el poder económico y político.

De cualquier forma, como apuntamos anteriormente el debate aún permite muchas interpretaciones.

Debemos establecer, para finalizar, la valoración en la funcionalidad de las representaciones. El objetivo de éstas era el de delimitar y proteger, de este modo unas imágenes rotas son incapaces de cumplir su función, las esculturas, por tanto, han fracasado en su cometido. 


\begin{tabular}{|c|c|c|c|c|c|}
\hline NECROPOLS & CR. USO & $\begin{array}{l}\text { CR.REUT- } \\
\text { LZACIÓN }\end{array}$ & REMATE & TPO & AUTOR \\
\hline AGOST & & & ES & $?$ & LLOBREGAT, 66 \\
\hline AGOST & & & $T$ & $?$ & LLOBREGAT, 66 \\
\hline AGUA SALADA & & v & $\mathrm{c}$ & P-E & CASTELO, 94 \\
\hline AGUA SALADA & $1 / 2 V$ & & $\mathrm{C}$ & $?$ & LILLO Y SERRANO 89 \\
\hline ALBUFERETA & V-111 & & FEM-MAS & $A R$ & FIGUERAS, 46 \\
\hline ALBUFERETA & & & ¿BICHA? & $?$ & LLOBREGAT, 66 \\
\hline ALBUFERETA & IV-III & & $T$ & & CHAPA 85 \\
\hline ALCOY & & IV & femenina & TR & ALMAGRO, $82 \mathrm{~b}$ \\
\hline ALCUDIA & & $\mathrm{V}$ & $L, 2$ & $\mathrm{~B}$ & CASTELO, 94 \\
\hline ALCUDIA & & $v$ & C, 2 & B & CASTELO, 94 \\
\hline ALCUDIA & & $\mathrm{V}$ & fems, sedentes, 4 & $\mathrm{~B}$ & CASTELO, 94 \\
\hline ALCUDIA & IV & & $P L, 3$ & P-E & CASTELO, 94 \\
\hline \begin{tabular}{|l|} 
ALCUDIA \\
\end{tabular} & IV & & GU, 9 & PT & CASTELO, 94 \\
\hline ALCUDIA & IV & & DAMA & BS & LLOBREGAT, 66 \\
\hline BALONES & & & $T$ & $?$ & LLOBREGAT, 66 \\
\hline BALONES & & & $T$ & $E X$ & CHAPA 85 \\
\hline BARCELONA * & $\mathrm{v}$ & & $T$ & $?$ & SANMARTI 87 \\
\hline BENIMASSOT & & & $\bar{T}$ & $E X$ & CORTELL, 89 \\
\hline BOCAIRENTE & & & $\mathrm{L}$ & TR & CHAPA, 85 \\
\hline C. DEL TESORO & & & ES & & NIETO, 40 \\
\hline C. DEL TESORO & & $\mathrm{v}$ & BT, paloma & $\mathrm{N}-\mathrm{O}$ & \begin{tabular}{|l} 
CASTELO 0,94 \\
\end{tabular} \\
\hline C. DEL TESORO & & V & hombre & B & CASTELO 94 \\
\hline C. DELTESORO & & & $\mathrm{C}$ & & NEETO, 40 \\
\hline C. DEL TESORO & & v & $L, 4$ & $\mathrm{P}-\mathrm{E}$ & CASTELO, 94 \\
\hline C. DEL TESORO & $\bar{v}$ & $V-N$ & BS-PL & P.E & CUADRADO, 87 \\
\hline C. LUCERO & $\bar{v}$ & ppo. IV & $\bar{T}$ & PT "P* & ARANEGUI, 93 \\
\hline C. LUCERO & $\mathrm{V}$ & ppo. IV & $\mathrm{L}$ & PT " $\mathrm{C}^{\prime \prime}$ & ARANEGUI, 93 \\
\hline C. LUCERO & $\mathrm{v}$ & ppo. N & $T$ & PT "B" & ARANEGUI, 93 \\
\hline C. LUCERO & $\mathrm{V}$ & ppo. IV & $T$ & $P T^{\text {"E" }}$ & ARANEGUI 93 \\
\hline C. LUCERO & $\mathrm{V}$ & ppo. IN & $T$ & PT "G" & ARANEGUI, 93 \\
\hline C. LUCERO & IV & & DAMA & $\mathrm{BS}$ & LLOBREGAT, 90 \\
\hline C. LUCERO & VI & tv & $\mathrm{PL}, 4$ & P-E & CASTELO 94 \\
\hline CARENCIA & IV-III & & $T$ & & LLOBREGAT, 75 \\
\hline CERRO SANTOS & & & \begin{tabular}{|c|c|} 
cabeza fem. 4 \\
\end{tabular} & $?$ & FERNÁNDEZ, 43 \\
\hline CERRO SANTOS & & & cabeza masc., 3 & ¿ADOSA-DA? & FERNANDEZ, 43 \\
\hline CIGARRALEJO & $\mathrm{v}$ & $\vec{v}-\mathrm{IV}$ & $\mathrm{C}, 2$ & ¿EX? & CUADRADO 84 \\
\hline CIGARRALEJO & $\mathrm{v}$ & $V-I V$ & $T, 2$ & PLINTO & CUADRADDO 84 \\
\hline CIGARRALEJO & $\mathrm{V}$ & $\bar{V}-\mathrm{N}$ & $L, 2$ & PLINTO & CUADRADO, 84 \\
\hline CIGARRALEJO & $\mathrm{v}$ & $V-I V$ & SER & $?$ & CUADRADO, 84 \\
\hline CIGARRALEJO & $\bar{v}$ & $\mathrm{~V}-\mathrm{IV}$ & ¿SIR-PAV? & PLINTO & CUADRADO 84 \\
\hline CIGARRALEJO & & $425-350 *$ & humana, paloma & $\mathrm{N}-\mathrm{O}$ & CASTELO 90 \\
\hline CIGARRALEJO & & $425-350^{\text {** }}$ & ¿humana? & $\mathrm{N}-\mathrm{O}$ & CASTELO, 90 \\
\hline CIGARRALEJO & & $425-350$ & BS fem. 2 & $\mathrm{~N}-\mathrm{O}$ & CASTELO 90 \\
\hline CIGARRALEJO & & $\mathrm{v}$ & $12, \bar{T} 1, C_{3}$ & $P-E$ & CASTELO 94 \\
\hline \begin{tabular}{|l} 
CIGARRALEJO \\
\end{tabular} & & $\mathrm{EV}$ & \begin{tabular}{|l}
$\mathrm{J}$ \\
\end{tabular} & PT & \begin{tabular}{|l} 
CASTELO 94 \\
\end{tabular} \\
\hline COAMBRA & & & GU & $?$ & CASTELD, 94 \\
\hline COMMBRA & $350-325$ & IV & $T, G U$ & $\mathrm{P}-\mathrm{E}$ & GARCIAC, 91 \\
\hline COIMBRA & & & $T$ & $P-E$ & ALMAGRO, 87 \\
\hline COIMBRA & IV-III & & J & $\mathrm{CP}$ & MUNOZ 83 \\
\hline COIMBRA & IV- III & & $T$ & $?$ & MUNO2, 87 \\
\hline CORRAL SAUS & $\mathrm{VI}$ & IV & femenina & P-E & ALMAGRO, 87 \\
\hline CORRAL SAUS & $\bar{v}$ & & garra & $\mathrm{P}-\mathrm{E}$ & APARICIO, 82 \\
\hline CORRAL SAUS & $\mathrm{V}$ & & $J, C$ & $\mathrm{BR}$ & APARICIO, 82 \\
\hline CORRAL SAUS & v & & humana & $\mathrm{BR}$ & APARICIO, 82 \\
\hline COY & & & $\mathrm{L}$ & $?$ & CHAPA 85 \\
\hline ESCUERA & & & $\mathrm{L}$ & $\overline{P T}$ & CHAPA 85 \\
\hline FONT CALENT & & & $\mathrm{L}$ & $?$ & CHAPA 85 \\
\hline FUENTE GARRULO & & $\mathrm{v}$ & $L$ & $\overline{P-E}$ & CASTELO 094 \\
\hline HUERTA MAYOR & ¿romana? & & fem tumbadas & TR & CASTELLO, 94 \\
\hline L.LOMA GALBIS & & & $\mathrm{L}$ & $?$ & LLOBREGAT, 66 \\
\hline MOLAR & & & $\bar{T}$ & & LLOBREGAT, 66 \\
\hline MOLAR & & & $\mathrm{L}$ & & LLOBREGAT, 66 \\
\hline MONFORTE CID & & V & $T$ & $P-E$ & CASTELO 94 \\
\hline MONFORTE CID & & $\mathrm{V}$ & $T, 2$ & $\mathrm{PT}$ & CASTELO 94 \\
\hline MONFORTE CID & & & $\bar{T}$ & $\bar{P}-\mathrm{E}$ & $A B A D, 91$ \\
\hline MONFORTE CID & $525-475$ & & $T$ & P-E & ALMAGRO y RAMOS, 86 \\
\hline MONTEAGUDO & & & PRÓTOMO & $?$ & GARCIAC. 91 \\
\hline MONTEAGUDO & & & G & $?$ & GARC|AC. 91 \\
\hline MONTEAGUDO & & & $\begin{array}{r}T \\
\end{array}$ & $?$ & GARCIAC , 91 \\
\hline MONTEAGUDO & & & GU & $?$ & GARCIA C . 91 \\
\hline NIETOS & & $\mathrm{V}$ & $T, 2$ & P-E & CASTELOO, 94 \\
\hline NIETOS & & $\mathrm{V}-\mathrm{IV}$ & $T$ & P-E & AL.MAGRO y CRUZ, 82 \\
\hline PARQUE ELCHE & & $\mathrm{V}$ & ES & TR & CASTELO 94 \\
\hline PARQUE ELCHE & $\overline{\mathrm{V}}-410$ & & $\overline{\mathrm{T}}$ & URNA & RAMOS FOLQUES, 50 \\
\hline PARQUE ELCHE & & $\mathrm{v}$ & $T, 2$ & PT & CASTELO 94 \\
\hline PARQUE ELCHE & & $\mathrm{V}$ & ES & TR & CASTELO, 94 \\
\hline PARQUE ELCHE & $V \mid-410$ & & $E S, 2$, & URNA & RAMOS FOLQUÉS, 50 \\
\hline PARQUE ELCHE & $\mathbf{v}$ & $V-I V$ & ES & $T R$ & ABAD 91 \\
\hline PINO HERMOSO & $2^{\mathrm{a} 1 / 2 \mathrm{IV}}$ & & personaje alado & TR & ALMAGRO y RUBIO, 80 \\
\hline PRADO & $2^{01 / 2 V}$ & & hurnana & P-E & GARCIAC C. 91 \\
\hline REDOVAN & & & torso fem: & & LLOBREGAT, 66 \\
\hline SAGUNTO & & & $T$ & $?$ & LLOBREGAT, 66 \\
\hline SAGUNTO & & & $\mathrm{L}$ & $?$ & LLOBREGAT, 66 \\
\hline SAX & & & $T$ & EX & CHAPA B5 \\
\hline TOSSAL,BENIDORM & & & $\mathrm{L}$ & & CHAPA 85 \\
\hline VILLAJOYOSA & IV-III & & $T$ & & LLOBREGAT, 74 \\
\hline VILLEENA & & & cabeza fom. & $?$ & ALMAGRO, 83 \\
\hline VIZCARRA & & & $L$ & $?$ & LLOBREGAT, 66 \\
\hline VIZCARRA & & & dama seconte & $?$ & LLOBREGAT, 66 \\
\hline VIZCARRA & & & $\mathrm{J}$ & $A R$ & LIOBREGAT, 66 \\
\hline ZARICEJO & & & $L(f \circ m)$ & $?$ & ALMAGRO, 83 \\
\hline
\end{tabular}


Notas de la Tabla:

* Bóvido aparecido en Barcelona, pero que parece proceder de Alicante o Murcia.

** Banda cronológica con valores máximos y mínimos. El número asociado al tipo de remate hace referencia a los casos aparecidos y citados por un mismo autor. En cursiva los tres ejemplos existente de pilares-estela de tipo Corral de Saus, ya que éstos representan un modelo un tanto especial.

Se ha prescindido de establecer repeticiones innecesarias, salvo en los casos de los pilares-estela del Corral de Saus, ya que Almagro $(1987,210)$ no identifica el animal que corona la estructura, y en el de Coimbra del Barranco Ancho, por la polémica existente entre los dos investigadores, Muñoz (1983 y 1987), y García Cano (1994).

Índice de abreviaturas empleadas:

AR: alto relieve; B: basamento; BR: bajo relieve; BS: busto; C: caballo; CP: cipo; ES: esfinge; EX: exenta; G: grifo; GU: guerrero; J: jinete; L: león; N-O: nicho hornacina; PE: pilar-estela; PAJ: pájaro; PL: palma; PT: plataforma; SER: serpiente; SIR: sirena; T: toro; TR: turriforme.

\section{BIBLIOGRAFÍA}

ABAD, L. y SALA, F. 1991: "Las necrópolis ibéricas del área de Levante". En BLÁNQUEZ, J. J. y ANTONA, V. (Eds.): Congreso de Arqueología Ibérica: Las necrópolis. UAM., Varia I, 145-167.

ALMAGRO, M. 1978a: "Pozo Moro y la formación de la Cultura Ibérica", Saguntum 13, 227-246.

ALMAGRO, M. 1978b: "Los relieves mitológicos orientalizantes de Pozo Moro", Trabajos de Prehistoria 39, 251 271.

ALMAGRO, M. 1982a: "El paisaje de las necrópolis ibéricas y su interpretación sociocultural", Revista di Studi Liguri, XLVI. Omaggio Nino Lamboglia, II, Bordighera, 199-219.

ALMAGRO, M. 1982b: "El monumento de Alcoy: aportación preliminar a la arquitectura funeraria ibérica", Trabajos de Prehistoria 39, 161-204.

ALMAGRO, M. 1983: Los iberos. Madrid, 159-164.

ALMAGRO, M. 1987: "El pilar-estela de las Damitas de Mogente (Corral de Saus, Mogente. Valencia)", A.P.L. XVII, 199-228.

ALMAGRO, M. y RUBIO F. 1980: "El monumento ibérico de Pino Hermoso (Orihuela, Alicante)", Trabajos de Prehistoria 37, 345-360.

ALMAGRO, M. y CRUZ M. L. 1981: "Los monumentos funerarios de los Nietos (Murcia)", Saguntum 16, 137-149

ALMAGRO, M. y RAMOS R. 1986: "El monumento ibérico de Monforte del Cid", Lucentum V, 45-63.

APARICIO, J. 1977: "Las raíces de Mogente. Prehistoria y Protohistoria", Serie Arqueológica del Departamento de Historia Antigua 2, 25-30.

APARICIO, J. 1982: "La necrópolis del Corral de Saus y las evidencias de una primera revolución social", Papers de la Costera II, 33-46.

APARICIO, J. 1988: "La tumba ibérica del Camí del Bosquet (Mogente, Valencia)", A.P.L. XVIII, 405-424.

ARANEGUI, C. 1991: "La necrópolis ibérica de Cabezo Lucero, (Guardamar del Segura, Alicante)". En BLÁNQUEZ, J. J. y ANTONA, V. (Eds.): Congreso de Arqueología Ibérica: Las necrópolis. U.A.M., Varia I, 169-187.

ARANEGUI, C., JODIN, A. y LLOBREGAT, E. 1993: La nécropol ibérique de Cabezo Lucero (Guardamar del Segura, Alicante). Mélanges de la Casa Velázquez, 69-84.

BENDALA, M. 1990: La antigüedad: de la Prehistoria a los visigodos, Serie Introducción al arte español. Madrid, 129132.

BLANCO, A. 1961: "El toro ibérico", Homenaje al profesor Cayetano de Mergalina. CSIC., 163-195.

BLANCO, A. 1986-87: "Destrucciones antiguas en el mundo ibérico y mediterráneo occidental", CUPAUAM 13-14, 3-8.

BLÁZQUEZ, J. M. 1962: Las religiones primitivas de España, Biblioteca E.E.H.A.R., 14 Roma, 189-195.

BLÁZQUEZ, J. M. 1974: Clases y conflictos sociales en la Historia. Madrid, 29-31.

CASTELO, R. 1990: "Nueva aportación al paisaje de las necrópolis ibéricas. Paramentos con nicho ornamental y posibles altares en la necrópolis del Cigarralejo (Mula, Murcia)", CUPAUAM 17, 35-43.

CASTELO, R. 1994: "Monumentos funerarios ibéricos: interpretación de alguno de los restos arquitectónicos y escultóricos aparecidos en las necrópolis del Sureste peninsular", Revista de Estudios Ibéricos 1, 139-171.

CORTELL, E., et alli, 1989: "Dos nuevas esculturas ibéricas en la Contestania. Toro y Dama de Benimassot", XIX C.N.A. vol. I, 543-550.

CUADRADO, E. 1984: "Restos monumentales funerarios de El Cigarralejo", Trabajos de Prehistoria 41, 251-270.

CUADRADO, E. 1985: "Las necrópolis ibéricas del Levante español", Iberos. Actas de la primera jornada mundial, 185-203.

CUADRADO, E. 1987: "Tres bustos ibéricos", A.P.L. XVIII, 275-277.

CHAPA, T. 1980: "Las esfinges en la plástica ibérica", Trabajos de Prehistoria 39, 309-344.

CHAPA, T. 1985: La escultura ibérica zoomorfa. Editorial Nacional. Ministerio de Cultura. Madrid.

CHAPA, T. 1986: Los influjos griegos en la escultura zoomorfa griega. Serie Iberia Graeca II. C.S.I.C. Madrid.

CHAPA, T. 1993: "La destrucción de la escultura funeraria ibérica", Trabajos de Prehistoria 50, 185-195.

FERNÁNDEZ AVILÉS, A. 1941: "Los toros hispánicos del Cabezo Lucero, Rojales (Alicante)", AEArq XLV, 513-523.

FERNÁNDEZ, A. 1943: "Escultura del Cerro de los Santos. La colección Velasco (Museo Antropológico), en el Museo Arqueológico Nacional", AEArq LIII, 361-387.

FIGUERAS, F. 1946: "El grupo escultórico de Alicante", AEArq XIX, 309-333.

GARCÍA BELLIDO, A. 1943: "De escultura ibérica. Algunos problemas de arte y cronología", AEArq LII, 272-297.

GARCÍA CANO, J.M. 1991: "Las necrópolis ibéricas en Murcia". En BLÁNQUEZ, J. J y ANTONA, V. (Eds.): Congreso de Arqueología Ibérica: Las necrópolis. UAM., Varia I, 313-347.

GARCÍA CANO, J.M. 1994: "El pilar-estela de Coimbra del Barranco Ancho (Jumilla, Murcia)", Revista de Estudios Ibéricos I, 173-201.

GARCÍA HUERTA, M. R. 1995: "La muerte y los rituales funerarios en el mundo ibérico", El mundo ibérico: una nueva imagen en los albores del año 2000. Junta de Comunidades de Castilla - La Mancha, 65-79.

GARCÍA-GELABERT, M. P. y BLÁZQUEZ, J. M. 1993: "Destrucción de la escultura ibérica: posibles causas", Homenaje a Miquel Tarradell, Barcelona, 403, 410.

GARCÍA-GELABERT, M. P. y BLÁZQUEZ, J. M. 1997: "Caráćter sacro y funerario del toro en el mundo ibérico", Quaderns de Prehistória i Arqueologia de Castelló 18, 417-442.

JORDÁ, F. 1976: "¿Restos de un culto al toro en el arte levantino?", Zephyrus XXVI-XXVII, 187-216.

LILLO, P. 1983: "Aportación al estudio de la religión ibérica: la diosa de los lobos de la Umbría de Salchite, Moratalla (Murcia)", XVI C.N.A., 769-781.

LILLO, P. y SERRANO, D. 1989: "Los fragmentos es- 
cultóricos ibéricos del Agua Salada (Alcantarilla, Murcia)", A.P.L. XIX, 77-88.

LUCAS, M. R. 1991: "Sociedad y religión a través de las necrópolis ibéricas". En BLÁNQUEZ, J. J. y ANTONA, V. (Eds.): Congreso de Arqueología Ibérica: Las necrópolis. UAM., Varia I, 189-205.

LLOBREGAT, E. 1966: "La escultura ibérica en piedra del País Valenciano. Bases para el estudio crítico contemporáneo del arte ibérico", AEArq XXXVII, 41-57.

LLOBREGAT, E. 1972: Contestania Ibérica. Alicante.

LLOBREGAT, E. 1974: "El toro ibérico de Villajoyosa (Alicante)", Zephyrus XXV. 335-342.

LLOBREGAT, E. 1975: "Escultura ibérica de la Edetania. La cabeza de toro de la Carència (Turís)", A.P.L. XV, 155160.

LLOBREGAT, E. 1982: "Toros y agua en los cultos funerarios ibéricos", Saguntum 16, 149-164.

LLOBREGAT, E. 1989: "Panorama de la escultura ibérica valenciana. Estado actual de la investigación", XIX C.N.A., 537-541.

LLOBREGAT, E. y JODIN, A. 1990: "La dama de Cabezo Lucero (Guardamar del Segura, Alicante)", Saguntum 13, 109-122.

MUÑOZ, A. M. 1983: "Cipo funerario decorado con esculturas", XVI C.N.A., 741-749.

MUÑOZ, A. M. 1987: "La escultura funeraria de la Necrópolis de Coimbra del Barranco Ancho (Jumilla, Murcia)", A.P.L. XVII, 229-248.

NIETO, G. 1940: "Noticias de las excavaciones realizadas en la necrópolis del Cabecico del Tesoro de Verdolay", B.A.E.A.A. 22-24, 191-196

OLMOS, R. 1991: "Religiosidad e ideología ibérica en el marco mediterráneo", Religiosidad y vida cotidiana en la Península lbérica. Fons Mellaria, 11-45.

PLA, E. 1975: "La necrópolis ibérica con sepulturas de empedrado tumular de Corral de Saus en Mogente (Valen- cia)", XIV C.N.A., 727-739.

QUESADA, F. 1989: "Sobre la cronología de la destrucción escultórica en la necrópolis de El Cabecico del Tesoro (Verdolay, Murcia)", B.A.E.A.A. 26, 19-24.

RAMOS FERNÁNDEZ, R. 1988: "Simbolismo de la esfinge de Elche", A.P.L. XVIII, 367-383.

RAMOS FERNÁNDEZ, R. 1989: "Vestigios de un posible monumento funerario ibérico en el Parque de Elche", XIX C.N.A., 507-515.

RAMOS FOLQUÉS, A. 1950: "Hallazgos escultóricos en La Alcudia, Elche", AEArq XXII, 353-359.

RAMOS FOLQUÉS, A. 1966a: "Estatigrafía de la Alcudia de Elche", Saitabi XVI, 71-76.

RAMOS FOLQUÉS, A. 1966b: "Fragmento de escultura ibérica de Elche", A.P.L. XI, 149-153.

RUANO, E. 1987a: "Primera gran destrucción escultórica en el mundo ibérico", B.A.E.A.A. 23, 58-62.

RUANO, E. 1987b: La escultura humana en piedra en el mundo ibérico, 86-122. Madrid.

SALA, F. 1996: "Algunas reflexiones sobre la fase antigua de la Contestania Ibérica: de la tradición orientalizante al periodo clásico", Anales de Arqueología Cordobesa 7, 9-32.

SÁNCHEZ, J. L. y QUESADA F., 1991 "La necrópolis ibérica del Cabecico del Tesoro (Verdolay, Murcia). En BLÁNQUEZ, J. J. y ANTONA, V. (Eds.): Congreso de Arqueologia lbérica: Las necrópolis. UAM., Varia I, 349-396.

SANMARTÍ, E. 1987: "Notas acerca de un bóvido ibérico en piedra del museo arqueológico de Barcelona", A.P.L. XVII, 261-273

TARRADELL, M. 1961: "Ensayo de estatigrafía comparada y de cronología de los poblados ibéricos valencianos", Saitabi XI, 3-20.

WALKER, M. J y LILLO, P. 1984: "Excavaciones arqueológicas en el Prado de Jumilla (Murcia). Campaña de 1980", Anales de la Universidad de Murcia, 4-29. 